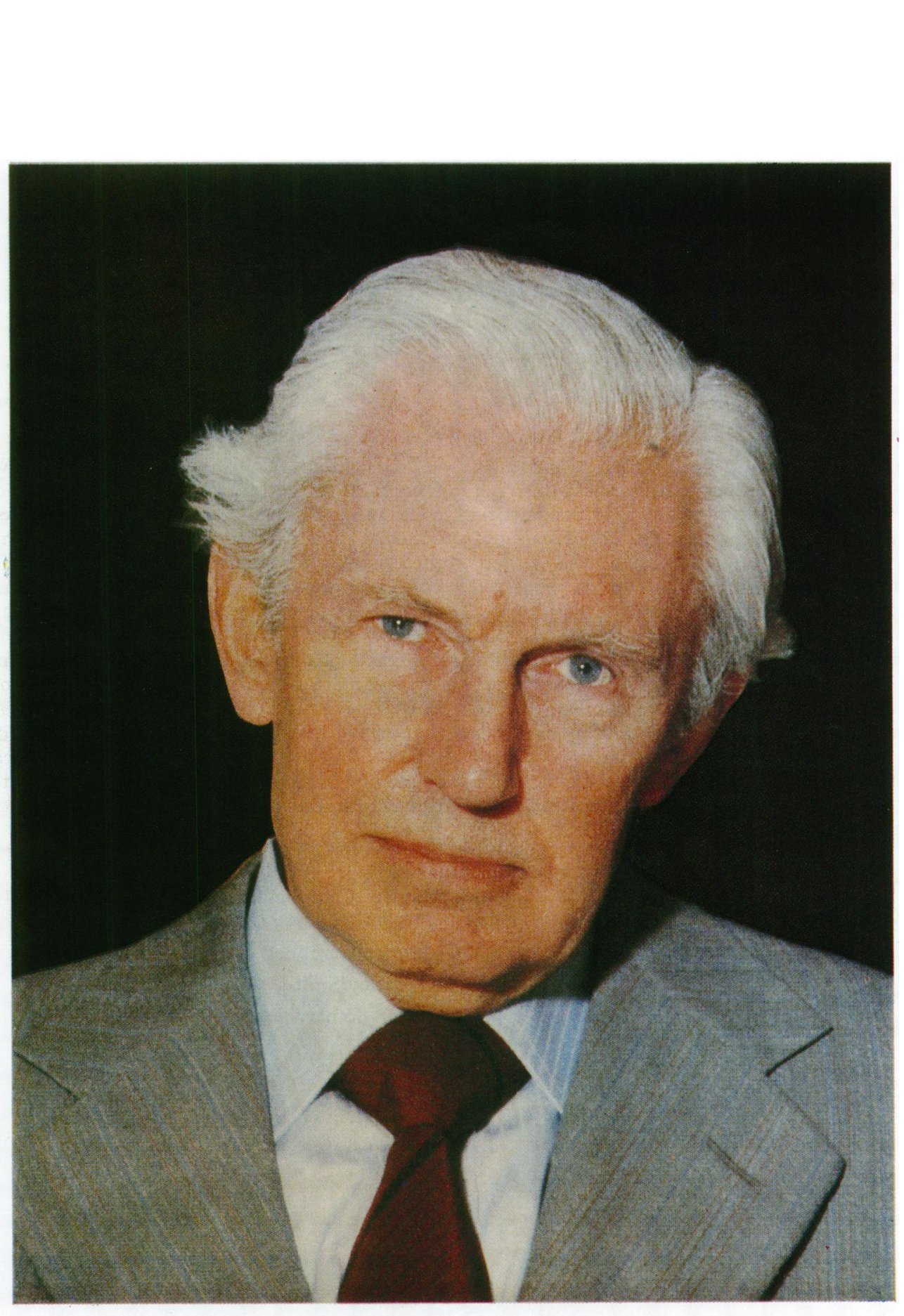

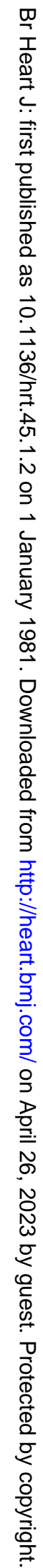




\title{
An appreciation of Walter Somerville
}

\author{
JOHN GOODWIN
}

I think I met Walter first at the Junior Cardiac Club in 1950 shortly after I was appointed to the staff of the Royal Postgraduate Medical School (then the Postgraduate Medical School of London). Walter, with Raymond Daley, had recently founded the Junior Cardiac Club as a forum for young registrars who were not members of the British Cardiac Society. I soon learned that Walter had studied in Boston at the Massachusetts General Hospital and the Peter Brent Brigham Hospital and had worked with the late Sam Levine. His research had included a study of the effects of adrenal cortical insufficiency on the heart. He had also studied in Paris and Stockholm.

Walter was medical registrar at the Postgraduate Medical School, Hammersmith, in 1947 and became consecutively medical registrar at the National Heart Hospital and then senior registrar in medicine at the Middlesex Hospital in 1951. His appointment as Physician to the Middlesex Hospital in 1954 came as no surprise. His work with Bedford and Sellors on the investigation and surgical treatment of atrial septal defect firmly established him among the front rank of cardiologists. At this time the late Paul Wood was opening up the frontiers of modern clinical cardiology and he at once recognised Walter's talents. The two became firm friends as well as colleagues. The deep friendship between Wood and Walter was based on mutual respect, admiration, and understanding between two complex but different personalities. Because of his profound understanding of the human scene it was perhaps not surprising that Walter, a dedicated Roman Catholic, should have established such a relation with Wood, a confirmed agnostic. Walter, as Wood's physician in his last illness, showed great compassion and insight, as would have been expected.

Walter remained a pillar of the Junior Cardiac Club for a number of years. A photograph taken by John Parkinson in his garden at Hampstead in the early $1950 \mathrm{~s}^{1}$ shows Walter in typical pose with his kind, quizzical, and understanding expression. For a time he wore a carnation in his buttonhole; now he no longer needs one. His elegance is established on the cardiological scene.

As the years went by I saw Walter regularly and came to appreciate his qualities, both as a man and a physician. His high professional standards, meticulous attention to detail combined with a deep knowledge of medicine, soon made him much sought after as a consultant. As a stickler for etiquette, he has always believed that the correct form must be observed. His insistence on protocol can be judged by his measured and meticulous speech and his delivery of well-turned phrases.

Walter's interest in research has continued, and in recent years his papers with Taggart and Carruthers on the effects of autonomic imbalance on the heart and electrocardiogram have attracted much attention.

I first appreciated Walter's knowledge and expert use of the English language when we were fellow assistant editors of the British Heart fournal. Later, when he had become editor, I was sometimes subjected to forthright but courteous admonitions for my shortcomings in the construction of English in the papers I submitted to the Journal. While my split infinitives may have been allowable, my dangling participles were apparently obnoxious and my tautology was abhorrent. I hope that since then, as a result of his advice, I have improved somewhat. Walter has been an outstandingly good editor of the British Heart fournal. He has consistently built up its reputation as probably the best journal of its kind now published. He has done this by hard work and a constant preoccupation with the attainment of excellence. One of his most engaging talents is his eagerness to welcome criticism of the Journal and of editorial policy, for he rightly sees discussion and argument as the lifeblood of a successful journal.

Many responsibilities have come to Walter, especially his appointments as civilian consultant to the Army and to the Royal Air Force, and his advisory roles in civil aviation. He has brought to all these activities his usual expertise and critical judgement. His many achievements were recognised by the award of the CBE last year.

Off duty, Walter is a connoisseur of fine wines and objets d'art and a bibliophile with a deep and wide knowledge of literature. A superb host, he makes his guests feel immediately at home and he treats them as people who are very special to him. 
These gifts spring from a deep sympathy with humanity and a genuine desire to understand his fellow creatures.

I have had the good fortune to accompany Walter on some visits to the Middle East and foreign parts by flying machine. Walter is a delightful travelling companion; witty, instructive, beguiling, and never boring. Furthermore, those who travel with Walter are fortunate because of his ability to deal with problems posed by recalcitrant travel personnel. This ability is unrivalled; never raising his voice and never showing pique or frustration he firmly disposes of obstructiveness and achieves the desired result with courtesy and without apparent effort. Inside the velvet glove lies, not an iron hand, but a fine stiletto. The riposte is of words, not of steel, and the sole casualty is the delicately transfixed ego of a local dignitary.

There is a mischievous streak in Walter. Some traces of the leprechaun have crossed the Irish Sea with him. I recall an incident in a well-known Middle Eastern airport. We were met by the representative of the Ministry whose name when pronounced in the English way had a close similarity to a short expressive word much used by British Other Ranks and by certain avant-garde novelists, but seldom employed in polite society. Walter told me his name in low tones and insisted that I address him firmly and loudly by this name because otherwise he would feel slighted. I demurred but Walter insisted. Naturally, I obeyed. As I did so all conversation in the VIP lounge ceased and my voice rang loud and clear. Four pairs of VIP eyes swivelled towards me like the barrels of 16-inch guns; the atmosphere was electric. Desperately I looked for Walter but he was deep in muted conversation in a corner. A small green figure perched on his shoulder winked at me before disappearing as suddenly as it had appeared. The only person who was delighted was our friend from the Ministry; later I learned that his name meant "happiness".

Most appreciations of distinguished people tend to appear after they have retired. It is a pleasure, therefore, to write this small piece at a time when Walter is as active as ever; President of the British Cardiac Society, in full clinical practice, writing papers, contributing to scientific meetings, and advising on many matters cardiological. I have often had cause to be grateful to Walter for his advice and he has served most helpfully and without complaint on my several working parties when I was President of the British Cardiac Society and Chairman of the Cardiological Committee of the Royal College of Physicians.

It is a pleasure to offer this appreciation of Walter Somerville, a good friend of many years, a great humanitarian, a notable cardiological scientist, an outstanding teacher, and a leader of British cardiology.

\section{Reference}

1 Campbell M. The British Cardiac Society and the Cardiac Club: 1922-1961. Br Heart f 1962; 24: 693.

Requests for reprints to Professor John Goodwin, Royal Postgraduate Medical School, Du Cane Road, London W12 0HS. 